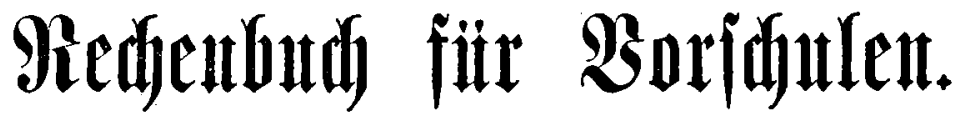

\author{
$\mathfrak{I} \|$ Dret $\mathfrak{S} \in \mathfrak{f t e n}$ \\ heraughegeben \\ bulı
}

3. 9utg6urger,

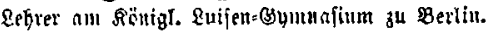

\section{Seft $I$.}

lifbungen im 3ablentreife bis 100 .

Bierte $\mathfrak{A} \mathfrak{n}$ flage.

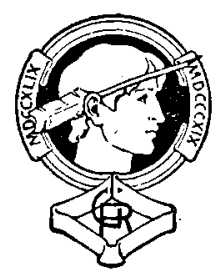

Berlin, 1898.

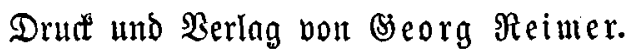





\section{Redyentudt fiir Boridullen.}

$\mathfrak{F} \mathfrak{n} \mathfrak{D} \mathfrak{e} \mathfrak{i} \mathfrak{S} \mathfrak{e} \mathfrak{f} \mathfrak{e} \mathfrak{n}$

herausgegebeu

von

3. Alugghurgex,

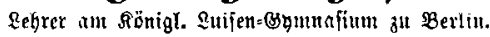

\section{$\mathfrak{S e f t}$ I.}

litbungen im $3 \mathfrak{a b l e n t r e t j e ~ b i s ~} 100$.

23ierte $\mathfrak{A}$ fifage.

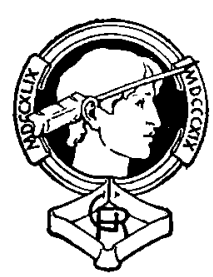

Berlin, 1898.

Druff und Berlag von Georg Reimer. 
